\title{
BRASIL PERIFÉRICA. LITERATURA MARGINAL DE SÃO PAULO
}

\author{
Lucía Tennina, editora \\ Editorial Cuarto Propio, 2016, pp. 257. \\ Christian Pardo-Gamboa \\ Pontificia Universidad Católica de Chile \\ christianpardogamboa@gmail.com
}

Durante los años 50, entre la periferia de las favelas y el centro de São Paulo, una mujer carretonera trabaja para alimentar a sus hijos, y en medio de los retazos de papel y cartón escribe su diario de vida. La anécdota nos relata que el periodista Audálio Dantas se encuentra con esta mujer, lee su diario y con su ayuda, Carolina María de Jesus publica en 1960 Quarto de despejo: Diário de uma favelada. Al año siguiente se publica en español y, con el tiempo, en más de diez idiomas. Quarto de despejo se vuelve un bestseller aclamado por una crítica interesada principalmente por su origen: una voz pobre que escribe. Sin embargo, Carolina de Jesus es rescatada en los 90 por un grupo de escritores, en especial poetas, que verán en su nombre y en el de otros autores como Plínio Marcos y João Antônio, los antecedentes de la "literatura marginal" de São Paulo.

Lucía Tennina, Doctora en Letras por la Universidad de Buenos Aires, es profesora de literatura brasileña y se ha dedicado a investigar la literatura contemporánea de las periferias de Brasil. Brasil Periférica: Literatura Marginal de São Paulo nos presenta una antología y una compleja síntesis del estudio de poetas que desde fines de los 90 comenzaron a gestionar una serie de experiencias y encuentros artísticos que luego consolidaron bajo el autodenominado concepto de "literatura marginal". Este trabajo de Tennina surge de una investigación iniciada el 2006 y que incluye un trabajo de campo durante el 2010-2011 en los saraus de São Paulo, espacios culturales de encuentro, discusión y lecturas. De esta forma, la autora pudo acceder a textos presentados en este libro que difícilmente se hubieran podido rescatar y presentar a nuestra comunidad hispanohablante.

Brasil Periférica ..., al igual que las voces marginales que se estudian, es una antología híbrida: mezcla crónicas, fragmentos de relatos, poesía, manifiestos, biografías y entrevistas; con el objetivo de generar un panorama literario versátil y complejo que, más que una pretensión sistemática totalizante, busca entregar "una invitación al lector a conocer un Brasil 
invisibilizado y a descubrir también el proceso actual por el que está transitando la literatura brasileña" (28).

El inicio del libro corresponde a una introducción que presenta una mirada cronológica acerca de las principales influencias y los antecedentes que permitieron la consolidación de estos escritores que desde los 90 se autodenominaron como marginales. En los manifiestos, las temáticas de sus escritos y la estética que se presenta en ellos encontramos como antecedentes el hip-hop de los 80, el privilegio de la palabra oral y la declamación propia de la literatura de cordel, la denuncia de la violencia y discriminación a través de la presencia negra, e incluso léxico y ritos cristianos típicos de las favelas de São Paulo. Lo "marginal", como señala la autora, propio de lo delictual, tendrá un desplazamiento semántico y pasará a ocupar un espacio en y desde el campo literario de la época. La motivación para dividir la primera parte del libro se basará en la propuesta de Peçanha do Nascimento (2011) que divide a los escritores marginales en dos grupos ${ }^{1}$ : una primera generación compuesta principalmente por autores que publicaron en los años 90 en la revista Caros Amigos, y una segunda generación que comenzó a escribir desde una periferia literaria ya consolidada y encontró en los saraus un espacio de difusión y posterior publicación. Organizar la antología en estos dos grupos generacionales "pretende, por un lado, dar cuenta del alcance en el tiempo que ha venido adquiriendo el movimiento de literatura marginal y, por otro, evidenciar la complejidad y versatilidad del mismo" (Tennina 27). La introducción avanza profundizando sobre elementos estéticos recurrentes y la forma en la cual se estructuró el libro, la investigación de campo realizada y los criterios de traducción que consideró, permitiéndonos acceder a este versátil sistema literario desde lo hispanófono.

La siguiente parte del libro se denomina "Primeras Voces" y corresponde precisamente a la primera generación de escritores marginales, donde encontramos autoras y autores como Sérgio Vaz, Binho, Elizandra Souza, Férrez, etc. Y también casos especiales como Dinha o GOG, rapero de Brasilia, quienes no participaron de las ediciones especiales de la revista Caros Amigos, pero se consideran una referencia de la primera generación y están vinculados tanto en sus textos como en sus redes amicales con los saraus de São Paulo. En esta primera generación de escritores encontramos muchos de los antecedentes, temas y

\footnotetext{
${ }^{1}$ Peçanha do Nascimento, E. É tudo nosso! Produção cultural na periferia cultural. 2011. Universidad de São Paulo, tesis de doctorado.
} 
estilos que consolidaron su posición en el campo literario brasileño contemporáneo, como se ve en "Mi poesía"" de Sérgio Vaz (Tennina 40):

Mi poesía,

A pesar de ser poca y rala

cabe en tu boca

dentro de tu habla.

A pesar de leve y ronca

llora en silencio

pero nunca se calla.

A pesar de ser lengua sin ropa, no traga papel, ¡escupe balas!
A mina poesía, a pesar de ser pouca e rala cabe na tua boca dentro da tua fala

A pesar de leve e rouca chora en silêncio mas nunca se cala

E a pesar da língua sem roupa não engole papel, cospe bala!

En este texto de Vaz se pueden encontrar resumidos algunos temas recurrentes de esta primera generación de escritores: evidencia el privilegio de la oralidad, la carencia de adornos poéticos, su posición "marginal” pero de permanente resistencia en el campo literario y una confrontación que no solo es política, sino también intelectual y estética. Además, encontramos en la antología otros temas que nos sintetiza Tennina, como la presencia y demanda desde lo afro-brasileño y lo femenino en contra de la violencia y discriminación. Elizandra Souza en "Legítima Defensa” comienza con una advertencia: "Solo estoy avisando, va a cambiar el marcador.../ Ya estoy viendo en los barrales los testículos de los hombres/ Que no saben comportarse" (56). Esta advertencia se estructura bajo la retórica de la anáfora: su repetición marca el inicio y término de cada estrofa y del poema en sí mismo, generando un ritmo de latencia y un tono de amenaza próxima a cumplirse.

La tercera parte del libro se sustenta en la figura del sarau como espacio central para este grupo de artistas de la segunda generación. El concepto refiere a reuniones en bares donde se lee, comparte y declama, alejándose del centro de São Paulo, lugar reconocido por sus actividades culturales. De esta manera los saraus se convirtieron en centros culturales de la periferia que potenciaron diversas actividades artísticas, lo que generó el reconocimiento

\footnotetext{
${ }^{2}$ Todas las traducciones de la presente reseña son de Lucía Tennina.
} 
y publicación en editoriales tanto independientes como comerciales. En esta sección encontramos una antología de 31 autores, inclusive textos inéditos transcriptos y traducidos por la autora para este libro: poemas y crónicas que profundizan los temas de la literatura marginal, la reescritura e intertextos con artistas de la primera generación y sus antecedentes literarios de mediados del siglo XX. La exploración de nuevas formas y temas será fructífero precisamente gracias al sarau: espacio artístico que, por sobre todo, generó comunidad; como señala Ni Brisant con el poema que cierra este capítulo: "Después de escucharme en los otros/nunca más hablé solo. /Mi monólogo es ahora/un diálogo diario.” (210).

La cuarta sección del libro nos traslada al género del manifiesto, textos recurrentes como pilares identitarios entre los y las artistas de ambas generaciones. El manifiesto, desde la perspectiva de Lucía Tennina es "la forma privilegiada para hablar de un 'nosotros' y exponer los principios programáticos, así como el repertorio de tópicos de un movimiento que se reconoce como una voz disruptiva frente al ordenamiento hegemónico del campo artístico" (28). La antología de este capítulo nos presenta cinco manifiestos: los primeros tres corresponden a los textos inaugurales de las ediciones especiales de la revista Caros Amigos que reúnen a los autores de la primera generación de literatura marginal. Estos tres manifiestos se pueden leer también como un solo texto: todos son firmados por Férrez como representante, están organizados en actos y se puede evidenciar un diálogo entre los tres textos en el transcurso de tiempo que va pasando entre cada publicación. Los manifiestos evidencian los integrantes que se van sumando, las posturas estéticas y políticas de este grupo de artistas, las dificultades que experimentan para instalarse dentro del campo literario, y, por otra parte, explicitan sus referentes, los conceptos teóricos de los cuales toman distancia y los antecedentes literarios que comparten. El cuarto manifiesto se titula "Nuestro Manifiesto. La elite tiembla", está firmado por el Colectivo Sarau Poesía na Brasa y, como señala la autora, es un texto que se suele escuchar en el sarau que lleva el mismo nombre, ubicado en la zona norte de São Paulo ${ }^{3}$. El último manifiesto está firmado por Sérgio Vaz y es el "Manifiesto de Antropofagia Periférica", el cual fue "declamado por primera vez en la Semana de Arte de la Periferia de São Paulo organizada por el Sarau de Cooperifa la semana

\footnotetext{
${ }^{3}$ Para más información, se puede revisar la página web del propio sarau, donde aparecen textos, recursos audiovisuales, mapas y conexiones con otros saraus: http://brasasarau.blogspot.com/

${ }^{4}$ Referente que retoma el "Manifiesto Antropófago" de Oswald de Andrade. (Revista de Antropofagia, vol. 1, núm.1, 1928)
} 
del 4 de noviembre de 2007" (28). Tanto los primeros tres manifiestos de la revista Caros Amigos como los últimos dos leídos y releídos en los saraus nos confirman la preponderancia de la oralidad, de la comunidad y de la resistencia de estos autores y autores del campo literario dominante.

La quinta sección del libro se denomina "Biografías": encontraremos no solo los nombres artísticos y reales de los artistas, sus orígenes y obras, sino que también en muchos casos leeremos sobre sus ideas, inspiraciones y concepciones acerca de la escritura, lo marginal y la literatura. La última parte son los "Anexos" y se presentan dos textos: El primero es un artículo titulado "Marginales \& Marginales" de Heolísa Buarque de Hollanda el cual hace un análisis del movimiento "poesía marginal” de los 70 y la consolidación del movimiento de "literatura marginal", los contextos productivos de ambos y las consecuencias de su inserción en el sistema literario brasileño. El libro de Lucía Tennina finaliza con una selección de entrevistas que la autora fue realizando en su trabajo de campo a muchos de los nombres que aparecen en la antología: ideas acerca del sarau, la retórica marginal, la condición de escritor marginal y la decisión de posicionarse desde la literatura son algunas respuestas sobre las que dialogan Binho Padial, Vaz, Férrez, da Rosa, Ferrari y Alessandro Buzo.

A mi juicio, Brasil periférica... es un trabajo crítico fundamental para los estudios literarios brasileños contemporáneos, el cual presenta un panorama complejo y heterogéneo que inevitablemente estrecha vínculos desde Brasil hacia el resto de Latinoamérica. Asimismo, Lucía Tennina nos presenta un trabajo coherente con la propuesta ética, estética y política de los escritores marginales de São Paulo al trabajar distintos tipos de discursos que incluye transcripciones, traducciones, manifiestos y entrevistas, lo que ofrece un elemento sociológico imprescindible de considerar en una literatura periférica. Finalmente, no deja de ser profundamente relevante estudiar este fenómeno literario, sus recursos estéticos y elecciones genológicas en un diálogo inevitablemente nutritivo: lo que reitera la importancia de reflexionar, releer y vincular estas voces con las hispanófonas del cono sur. 